Gut, 1988, 29, 173-180

\title{
Effects of osmoreceptor stimulation on human duodenal motor activity
}

\author{
D G THOMPSON AND D L WINGATE \\ From the Department of Gastroenterology, The London Hospital Medical College, Whitechapel, London
}

SUMMARY The motor responses of the human duodenum to saline solutions of varying osmolality were examined in order to investigate the possible role played by the upper intestine in the control of gastric efflux of hyperosmolar material. During fasting, delivery of the solutions into the duodenum increased duodenal motor activity and intraduodenal pressure, the magnitude of the response increasing with osmolality. At the highest osmolalities, a regular duodenal motor pattern was induced in some individuals which was indistinguishable from fasting phase III activity. After feeding, hyperosmolar saline again increased motor activity. In addition, the transit of an intraduodenal marker to the caecum was accelerated. These findings support the concept that the duodenum is both sensitive and responsive to its intraluminal content. The motor responses additionally appear to function to clear excessively stimulating intraluminal material from the duodenal lumen and may also contribute to the 'postpyloric' resistance which is known to exert control of normal gastric emptying.

The mucosa of the duodenum is known to be sensitive to the $\mathrm{pH}$, osmolality and lipid composition of its intraluminal content.' Intraduodenal nutrient outside an acceptable range for any of these constituents slows the passage of food from the stomach until the efflux is rendered more acceptable by further gastric secretion. The duodenum thus provides the sensory limb of a negative feedback loop regulating the passage of ingested material through the upper gut.

Of the three stimulants, osmolality has been the most common choice for study of this feedback system. ${ }^{23}$ Evidence now points to the existence of a functional, if not anatomical osmoreceptor, in the mucosa of the upper duodenum, the jejunum and ileum appear much less responsive. ${ }^{3}$ The site of the receptor seems to be internal to the mucosal brush border, because disaccharide solutions which are split by brush border enzymes exert twice the stimulatory action of equiosmolar solutions of monosaccharide. ${ }^{4}$

Address for correspondence: Dr D G Thompson, Department of Medicine Hope Hospital, Eccles Old Road, Salford M6 8HD.

Received for publication 31 July 1987.
Responses to human duodenal osmoreceptor stimulation seem to operate over a wide range. Hunt $^{2}$ found a roughly linear relationship between osmolality and duration of gastric inhibition from 500 mosmol $/ \mathrm{kg}$ to $1000 \mathrm{mosmol} / \mathrm{kg}$, although the upper limit of this relationship was not identified.

Although this regulatory function has been long recognised $^{5-7}$ our understanding of the mechanisms by which such control is effected on gastric efflux remains incomplete. The normal passage of food through the stomach and duodenum is the result of a complex interaction between gastric fundal tone, ${ }^{8}$ the pylorus $^{9}$ and, a further resistance factor ${ }^{10} 11$ which resides in duodenum and is independently capable of retarding intraluminal flow. So far, the nature of this duodenal resistance factor has not been identified with any certainty and its existence in man is unexplored.

We now report a series of experiments which were designed to explore the inter-relationships between human duodenal osmoreceptor stimulation and duodenal motor activity, together with study of the functional consequences of such activity upon intraluminal transit. 


\section{Methods}

SUBJECTS

Studies were carried out on healthy adult volunteers (age 21-35 years). All experimental protocols were approved by the local ethics committee and all subjects gave their informed consent prior to study.

\section{FASTED STUDIES}

On the morning after an overnight fast, nine subjects were intubated with a multilumen polyvinylchloride tube, manipulated with the aid of fluoroscopy until its tip lay at the duodenojejunal junction. This tube enabled test solutions of varying osmolality to be delivered into the second part of the duodenum through one channel, while four others (internal diameter $0.6 \mathrm{~mm}$ ) perfused with distilled water via a standard pneumohydraulic pump system and opening at $10 \mathrm{~cm}$ intervals from the tip, allowed detection and measurement of intraluminal pressure changes in the gastric antrum and the upper, mid and lower duodenum, through attached pressure transducers (Gaeltec Ltd, Dunvegan, Skye, UK). The outputs of these transducers connected to a multichannel chart recorder (Linearcorder, Watanabe Ltd, Japan) run at $2.5 \mathrm{~cm} / \mathrm{min}$ provided a permanent record of intraluminal pressure activity at each site. The tube also allowed intraduodenal contents to be sampled by aspiration through the central lumen, which opened at the distal end of the tube.

After satisfactory tube placement, subjects moved from the fluoroscopy room to the clinical study area where they reclined on a hospital bed for the duration of the study.

\section{EXPERIMENTAL CONDITIONS}

Pilot studies done by administering hyperosmolar solutions during different phases of fasting motility in one individual indicated that an increase in frequency of duodenal contractions would occur. For the present study therefore, all test solutions were delivered during phase I of the fasting periodic motor cycle. ${ }^{12}$ This phase was selected because of its characteristic quiescence, its ease of detection by reference to the preceding phase III, and because its relative refractoriness to external stimuli ${ }^{13}$ would reduce the possibility of false positive results. The pilot studies also indicated that the minimum volume of test solution which would reliably induce a motor response was $20 \mathrm{ml}$, delivered into the second part of the duodenum over one minute.

Seven normal subjects underwent duodenal stimulation using a series of test solutions of sodium chloride of differing osmolality. Seven solutions (including controls) were chosen for study in each individual, this number being selected to be achiev- able within a 12 hour study period, given that the average fasting motor cycle periodicity in man is 90 to 100 minutes. ${ }^{14}$ One test solution was delivered during each spontaneously occurring phase I period.

Osmolalities of the solutions ranged from 280 , through 560,1680 , and 3360 , to $5040 \mathrm{mosmol} / \mathrm{kg}$. The first three values were chosen to cover the likely range of osmolality found during food ingestion, the other two were included to identify patterns of response at greater levels of stimulation.

All solutions were made by dissolving sodium chloride crystals (Analar grade, BDH Chemicals Ltd, Poole, England) in distilled water, the eventual osmolalities of the solutions being determined by use of a Vapour pressure osmometer (Wescor Inc, Utah, USA). During the studies, solutions were kept in a water bath at $37^{\circ} \mathrm{C}$, the order of delivery of test solutions was randomised and subjects remained unaware of the nature of the solutions delivered.

To control for possible distension effects of the solutions on duodenal motor activity, two other infusions were delivered. The first consisted of $50 \mathrm{ml}$ of isosmolar saline infused at a rate of $20 \mathrm{ml} / \mathrm{min}$. The second was a sham infusion; a syringe was connected to the tube but no saline was delivered.

Ten minutes after delivery of each solution, the duodenal contents were aspirated, and the osmolality of the fluid obtained was compared with that of the solution delivered, thus providing an index of intraluminal dilution.

Subjective responses to the delivery of each solution were recorded from all individuals, in particular, symptoms of nausea, and abdominal discomfort were sought. Two individuals also repeated the study on a separate occasion in order to permit an assessment of the reproducibility of the responses obtained.

\section{FED STUDIES}

To determine the effect of duodenal osmoreceptor stimulation on postprandial duodenal motor activity and intraluminal transit, seven subjects were studied on two separate occasions, after per oral duodenal intubation using the technique described for the fasting studies. Small intestinal transit was additionally estimated by serial measurement of exhaled breath hydrogen concentration using a hydrogen sensitive electrochemical cell (GMI Ltd, Renfrew, Scotland). For each study a standard liquid mixed nutrient meal $(500 \mathrm{ml}, 260 \mathrm{cal}, 220 \mathrm{mosmol} / \mathrm{kg})$ comprising 25 gm glucose, and homogenised egg in water was ingested during fasting antroduodenal phase II activity. This meal was selected because in pilot studies it induced a typical fed pattern for at least 60 minutes, but did not produce a rise in exhaled breath hydrogen. Fifteen minutes after meal inges- 
tion, when a typical fed motor pattern had been established, a solution comprising $3 \mathrm{~g}$ lactulose in 30 $\mathrm{ml}$ water (osmolality $500 \mathrm{mosmol} / \mathrm{kg}$ ) was delivered directly into the second part of the duodenum at a rate of $20 \mathrm{ml}$ per minute. Earlier studies ${ }^{15}$ indicated that this solution would not measurably alter the duodenal motor pattern but would produce a detectable breath hydrogen rise upon its arrival at the caecum.

After the lactulose instillation, $20 \mathrm{ml}$ saline were delivered into the duodenum. On one occasion the solution was isosmolar $(280 \mathrm{mosmol} / \mathrm{kg})$ while on the other it was hyperosmolar $(1680 \mathrm{mosmol} / \mathrm{kg})$, the order of delivery being randomised for each individual. As in the fasted studies, the number of antral and duodenal contractions were counted in the 10 minute period after the saline infusion. In addition, duodenocaecal transit was estimated by measurement of the interval between delivery of the lactulose solution and the onset of a breath hydrogen rise, defined as a sustained rise lasting at least 20 minutes and exceeding baseline values at least two fold.

\section{ANALYSIS OF DATA}

Because initial inspection of the data indicated that the results were not normally distributed, statistical analyses were done using non-parametric techniques, ${ }^{16}$ the particular analyses used in each experiment being indicated where appropriate in the results section. To eliminate artifact as far as possible from the analysis of duodenal motility tracings, only those contractions which exceeded the respiratory excursion by a factor of two were included. Contractions which appeared simultaneously on all channels, suggesting extra intestinal artifact, were also excluded from study.

Net intraluminal pressure was defined as the sum of the amplitudes of the contractions recorded during the test period.

\section{Results}

\section{FASTED STUDIES}

\section{Duodenal motor activity}

With all but the most dilute solutions a rapid alteration in the pattern of duodenal motility occurred, changing from the expected quiescence of phase I to one characterised by irregular motor activity, the onset of the response usually appearing before the completion of the infusion.

In five of the nine subjects, a phase III-like duodenal motor pattern characterised by regular contractile activity at a frequency identical to that of the preceding fasting phase III activity and lasting at least two minutes was seen to follow the delivery of at least one of the more hyperosmolar solutions. This pattern was recorded in all duodenal channels in three subjects and in the lower duodenal channel only in two subjects. After this activity, a period of motor quiescence was also observed. Retrogradely propagating motor activity, sometimes associated with impending emesis, ${ }^{17}$ was not seen in any study.

Because of the infrequency of occurrence of spontaneous phase III activity in some subjects, not all solutions could be delivered to each individual within the time available for the study. Furthermore, the occurrence of untoward symptoms in a subject after a particular test solution precluded the delivery of solutions of greater osmolality to that individual.

Seven subjects received no infusion, six the 280 mosmol saline, nine the 560 mosmol saline, seven the 1680 mosmol saline, eight the 2520 mosmol saline, seven the 5040 mosmol saline and six the $50 \mathrm{ml}$ isomolar saline control. Phase III-like activity occurred in one subject after 1680 mosmol saline, in three after 2520 mosmol saline and in one subject, after 5040 mosmol saline.

The number of contractions occurring in the 10 minute period after the delivery of the test solutions for the group are shown in Figure 1. It is apparent that as the osmolality of the test solution rose, the number of contractions increased. The significance of this trend was first examined using Freedmans 2 way analysis of variance; for any missing points, the median value for the group was used. A significantly positive trend in frequency of contractions with increasing osmolality was shown for the mid and lower duodenal recording sites $(p<0.01)$ but not for the upper duodenum $(\mathrm{p}>0 \cdot 05)$.

In order to determine the overall significance of this response, at each recording site, Spearmans rank correlation coefficient was calculated for each individual, between the motor response and the solution osmolality.

For the mid and lower duodenal recording sites, all subjects showed a positive correlation coefficient indicating that as the osmolality of solutions increased an increase in motor activity occurred. Consistent differences were also found between the grouped correlation coefficients at the three duodenal sites, comparing upper with mid, and mid with lower duodenum ( $p<0.01$ Wilcoxon's matched pairs), indicating that the magnitude of the motor response increased along the duodenum.

To determine whether intraluminal distension could have made a significant contribution to this effect, the grouped data from the sham-infusion, the $20 \mathrm{ml}$ isosmolar, and the $50 \mathrm{ml}$ isosmolar experiments were compared. No significant differences between any of these sets of data were found $(>0 \cdot 05)$.

Because the occurrence of the phase III-like pattern could conceivably have increased the signifi- 
cance of the above analyses, the data were reexamined after exclusion of those results which showed this pattern. The general increase in duodenal motility activity with osmolality persisted $(p<0.05$ Spearman rank correlation) indicating the presence of an effect independent of the induction of phase III-like activity.

No significant change in median amplitude of contractions accompanied the change in frequency with osmolality ( $p>0.05$ Spearman rank correlation), but the net intraluminal pressure during the test periods was significantly increased in the mid and lower duodenum as osmolality increased $(\mathrm{p}<0.01$ Spearman rank correlation), indicating a stimulationdependent rise in net intraduodenal pressure. On many occasions, an increase in intestinal 'tone' also seemed to occur. This was indicated by the occurrence of a persistent rise of baseline pressure between contractions and was particularly marked during the periods of regular contractile activity, when baseline rises of 5-10 mm mercury were noted.

\section{Antral motor activity}

In contrast to the changes observed in the duodenum, no change in antral motor activity occurred. Antral quiescence, characteristic of phase I activity, persisted throughout the infusion of all solutions in all subjects, including those associated with the induction of duodenal phase III-like activity.

\section{Intraluminal osmolality}

Aspiration of the duodenal contents was attempted at the end of each study period. On only eight occasions, however, were samples obtained, despite persistently demonstrable patency of the tube, indicating that pooling of fluid had not occurred in the duodenum. The osmolalities of the aspirates were always between $40-70 \%$ of the solution delivered, indicating that the maximum intraluminal dilution

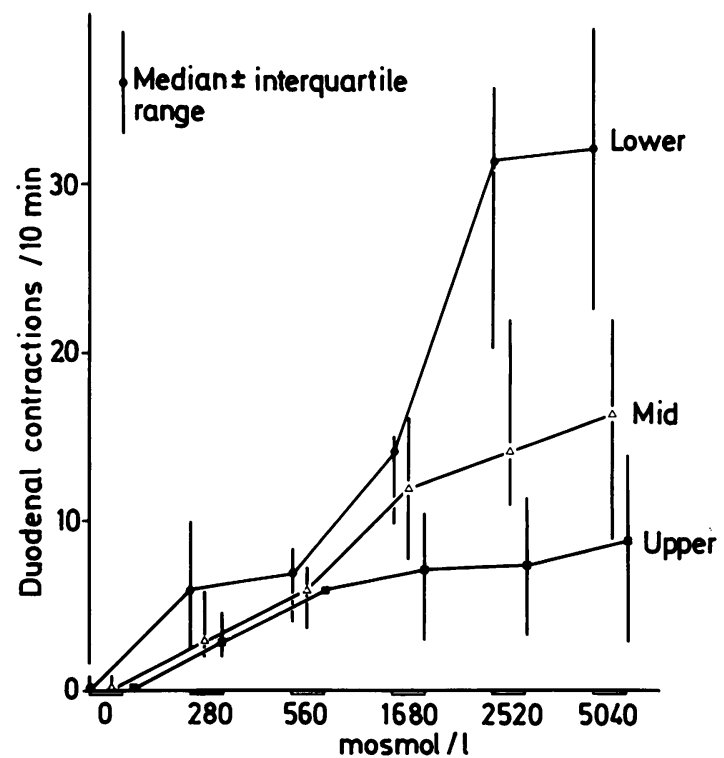

Fig. 1 Duodenal motor responses to saline solutions of increasing osmolality are shown. Values represent median \pm interquartile ranges for the group. With increasing osmolality the number of duodenal contractions also increases, the respose being greatest in the lower, and least in the upper, duodenum.

was unlikely to have been more than threefold. This result taken together with the absence of motor responses to the $50 \mathrm{ml}$ isosmolar control infusion suggests that distension was unlikely to have played a major role in inducing the observed motor response.

\section{Repeat studies}

Both subjects who repeated the study showed a similar pattern of motor response with increasing osmolality on both occasions (Table 1), including the

Table Number of duodenal contractions recorded in the 10 minute period after test solution delivery are shown for the two subjects who repeated the study. Figures in brackets indicate the data for the second study, asterisks indicate the occurrence of phase III-like activity, the presence of a hyphen indicates that a particular study was not performed.

\begin{tabular}{|c|c|c|c|c|c|c|c|}
\hline & $\begin{array}{l}\text { Infusion } \\
(n)\end{array}$ & $\begin{array}{l}(20 \mathrm{ml}) \\
280\end{array}$ & $\begin{array}{l}(50 \mathrm{ml}) \\
280\end{array}$ & 560 & 1680 & 2520 & 5040 \\
\hline \multicolumn{8}{|l|}{ Subject 3} \\
\hline \multicolumn{8}{|c|}{ Duodenum: } \\
\hline Upper & $7(8)$ & $0(-)$ & $8(-)$ & $9(19)$ & $22^{*}\left(69^{*}\right)$ & $-(-)$ & $-(-)$ \\
\hline Mid & $2(5)$ & $2(-)$ & $2(-)$ & $8(18)$ & $22^{*}\left(58^{*}\right)$ & $-(-)$ & $-(-)$ \\
\hline Lower & $14(17)$ & $17(-)$ & $16(-)$ & $12(19)$ & $80^{*}\left(71^{*}\right)$ & $-(-)$ & $-(-)$ \\
\hline \multicolumn{8}{|l|}{ Subject 7} \\
\hline \multicolumn{8}{|c|}{ Duodenum: } \\
\hline Upper & $0(0)$ & $2(0)$ & $3(-)$ & $5(0)$ & $6 \quad(-)$ & $4(2)$ & $8(-)$ \\
\hline Mid & $1(0)$ & $2(1)$ & $1(-)$ & 1 (4) & $3(-)$ & 2 (3) & $0(-)$ \\
\hline Lower & 0 (1) & $5(4)$ & $0(-)$ & $6(4)$ & $14(-)$ & $10(21)$ & $18(-)$ \\
\hline
\end{tabular}




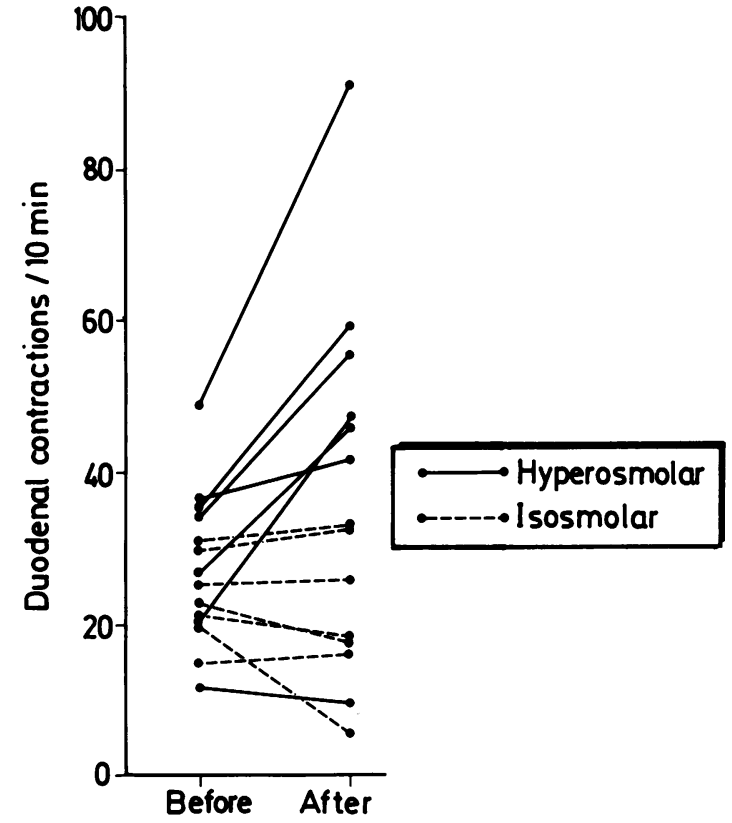

Fig. 2 Number of contractions occurring in mid duodenum are shown for each individual both before and after either isosmolar or hyperosmolar saline. No change in motility is seen after isosmolar saline. In contrast, an increase in motility is seen to follow delivery of hyperosmolar saline into the duodenum.

development of phase III-like activity at the same threshold in one subject.

\section{Symptoms}

Four of the five subjects who showed phase III-like activity admitted to a feeling of nausea two to three minutes after completion of solution delivery, but none vomited. The other subject in whom a phase III pattern was noted, did not feel nauseated. No other specific symptoms were noted during any of the studies in any subject.

\section{FED STUDIES}

Duodenal motor activity

In all seven subjects, the ingestion of the test meal induced a fed pattern, characterised by an increase in frequency of irregular contractile activity at all recording sites.

This pattern was not measurably altered by intraduodenal administration of either the lactulose solution or the isosmolar saline. The instillation of hyperosmolar saline into the duodenum was, however, followed in all subjects by an increase in both the number of duodenal contractions and net intraluminal pressure in all duodenum channels for at least 10 minutes postdelivery $(\mathrm{p}<0 \cdot 05$, Wilcoxon matched pairs) (Fig. 2). In no instance, however, did a regular contractile pattern resembling phase III activity result.

\section{Antral motor activity}

Postprandial motor activity was inconsistently detected using the single antral recording channel and data were inadequate for analysis.

\section{Duodenocaecal transit}

All individuals showed a rise in exhaled breath hydrogen during both studies permitting an estimate of duodenocaecal transit to be made. In all individuals the rise in exhaled breath hydrogen occurred earlier after delivery of the hyperosmolar saline than after the isosmolar saline (Fig. 3) $(\mathrm{p}<0.05$ Wilcoxon's matched pairs), indicating that duodenocaecal transit was more rapid.

\section{Discussion}

In his classic studies of the duodenal osmoreceptor, ${ }^{27}$ Hunt was able to identify a functional entity, deep to the brush border of the duodenal epithelium with a threshold of $500 \mathrm{mosmol} / \mathrm{kg}$ for inhibition of gastric emptying. More recent studies ${ }^{3}$ have also shown a similar threshold value, which is consistent with our own data.



Fig. 3 Time to onset of a consistent breath hydrogen rise is shown for each individual after delivery of both isosmolar and hyperosmolar saline. In all individuals the delivery of hyperosmolar saline was associated with reduction in time to breath hydrogen rise, indicating an acceleration of orocaecal transit. 
In addition to being able to sense the quality of gastric efflux, our results show that the duodenum is also responsive to its intraluminal content and increases its motor activity as the magnitude of the stimulus increases. The stimulus dependent nature of this duodenal motor response and the net rise in intraluminal pressure which results suggests that it may contribute to the putative postpyloric resistance mechanism ${ }^{7111}$ which is known to influence gastric emptying, but which has not previously been characterised. Although it is often intuitively assumed that increased small intestinal motility will speed transit, evidence for a negative relationship, with increased small intestinal activity resulting in delayed nutrient transit, ${ }^{18}{ }^{19}$ has been established. Gregory ${ }^{18}$ perfused canine Thiry-vella loops of jejunum with solutions of varying osmolality and found that as the osmolality increased, an accompanying increase in intestinal tone and contractile activity occurred, which retarded passage of fluid through the loop. A relationship between duodenal motility and gastric emptying has also been noted during studies of gastric emptying using meals of varying lipid content,${ }^{10}$ those which maximally retarded gastric emptying, were associated with the greatest increase in duodenal motor activity.

Since it has been reported that intraluminal distension of the human small intestine is itself able to stimulate motor activity, ${ }^{20}$ it could be hypothesised that the observed motor responses were the result of distension caused by a secretory response to the hyperosmolar solutions. Certainly the osmolalities of the duodenal aspirates indicate that intraluminal dilution of the infused solutions did occur during the period of study. The rapidity of the response, the small degree of intraluminal dilution, and the frequent absence of intraluminal content at a time when a motor response was still present must, however, argue against the importance of such distension, compared with direct motor stimulation, as the factor responsible.

The duodenal motor responses we have observed do not seem to be unique to osmoreceptor stimulation, but have also been noted by others after stimulation of the duodenum by acid. ${ }^{1922} 22$ In addition to inducing irregular duodenal motor activity, phase III-like patterns were also seen, which originally led to speculation that passage of gastric acid into the duodenum was the mechanism for initiation of duodenal phase III. ${ }^{21}$ The occurrence of normal fasting duodenal motility during suppression of acid secretion, ${ }^{22}$ however, seems to refute this hypothesis, and taken together with our data suggests that increased duodenal motor activity is probably nonspecific response to receptor stimulation.

The frequent occurrence of nausea in association with the phase III-like pattern in our study suggests that the two may be related. Similar phase III-like activity is also seen during nausea induced by other stimuli, ${ }^{1723}$ so that its appearance after stimulation again seems likely to be non-specific.

The accelerated transport of lactulose through the small intestine after the hyperosmolar saline suggests that the motor activity induced by duodenal stimulation may serve the additional function of clearing intraluminal material for its lumen, in addition to retarding gastric efflux. While further studies of this response are required to distinguish the contribution made by intestinal secretion from any direct motor effects, it is interesting to note that accelerated intestinal transit of hyperosmolar duodenal content together with increased motor activity was recognised in early radiological studies. ${ }^{2426}$ In these reports of the intraluminal passage of hyperosmolar barium/ glucose solutions, the first portion of the test meal to leave the stomach was consistently transported into the midjejunum in association with increased duodenal motor activity while gastric emptying was retarded. It seems possible that this transit effect serves to provide a means whereby hyperosmolar material is removed from the duodenum, thus allowing a 'resetting' of the receptor and the later resumption of emptying of gastric content rendered less hyperosmolar by gastric secretion.

While the exact pathways mediating the responses which we have observed cannot be determined with certainty from our experiments, it seems likely that two separate mechanisms are responsible. The initial dose dependent motor response closely resembles that observed by other workers using extrinsically denervated intestinal loops ${ }^{1827}$ suggesting that local, myenteric plexus modulation is responsible. It is known from the effects of exogenous peptides that the timing of phase III is a function of the enteric nervous system, so it is possible that all the effects shown by us are caused by local stimulation and modulation of the enteric nervous system. On the other hand the close association of nausea with phase III in our studies and the vagal dependence of this phenomenon $^{22}$ suggests that central modulation is also involved.

The relevance of our data to the normal control of upper gastrointestinal transit and digestion in daily life obviously depends on the original osmolality of food eaten and the rapidity with which it is digested to osmotically active particles. While comprehensive details of intraluminal osmolalities in the stomach and duodenum after ingestion of different foodstuffs are lacking, published data do show ${ }^{28}$ that even the simplest meals induce intragastric osmolalities which would induce a duodenal motor response. Our own laboratory survey also indicates that most western 
European meals are capable of stimulating a duodenal motor response and some may even exceed $1500 \mathrm{mosmol} / \mathrm{kg}$, in the case of highly seasoned soups and stews.

It must be accepted that the duodenal responses which we have found cannot be the sole mechanism for gastric efflux control. Gastric and pyloric responses will also play a role in retarding emptying and which process is the most important under normal circumstances is difficult to determine.

Further studies are now required to explore these interrelationships between gastric, pyloric and duodenal activity in greater detail, perhaps using a perfusion system with multiple orifices sited close together in the antro-duodenum so that simultaneous responses could be examined. In order to determine whether the duodenum does actually function as a 'brake', flow measurements with and without duodenal stimulation are required, so that rates of flow under pressures which equate with gastric emptying forces, can be measured. A recent method developed in dogs using an intraluminal flowmeter ${ }^{29}$ seems to show potential for such measurements in man and might allow study of these currently unanswered questions.

Although it is possible that the duodenum may not normally play a dominant role in nutrient transit control, it seems likely that it would assume much greater importance under certain circumstances. For example, after truncal vagotomy, receptive relaxation of the fundus is known to be impaired, intragastric pressure is higher, and emptying of fluids tends to be more rapid than normal. ${ }^{3031}$ Evidence exists $^{32}$ to indicate that the duodenum does remain responsive to receptor stimulation postvagotomy and that emptying of hyperosmolar solutions is delayed, even though it remains more rapid than before surgery. As patients with diarrhoea postvagotomy are characterised by more rapid emptying of gastric contents than those without diarrhoea ${ }^{33}$ it is possible that the intrinsic efficiency of the duodenal braking mechanism in an individual may determine whether or not symptoms develop. Those individuals with the least effective duodenal response to nutrient stimulation may be those most prone to develop diarrhoea postvagotomy. Studies of the upper gastrointestinal responses to hyperosmolar stimuli in individuals pre and postsurgery would allow this hypothesis to be tested.

The authors wish to thank Mr S J W Evans for providing valuable statistical advice and Ms Julie Rostron for preparation of the manuscript. P Binfield, A Burnett, A De Belder, P Perkins, D Salvage, S Warren, M Wilson, contributed to the studies whilst undertaking intercalated BSc degrees in Physiology at the London Hospital Medical College. Dr Thompson was a Wellcome Trust Senior Lecturer in Medicine.

\section{References}

1 Cooke AR, Control of gastric emptying and motility. Gastroenterology 1975; 68: 804-16.

2 Hunt JN. Some properties of an alimentary osmoreceptor mechanism. J Physiol 1956; 132: 2677-88.

3 Meeroff JC, Go VLW, Phillips SD. Control of gastric emptying by osmolality of duodenal contents in man. Gastroenterology 1975; 68: 1144-1.

4 Elias E, Gibson GJ, Greenwood LF, Hunt JN, Tripp $\mathrm{JH}$. The slowing of gastric emptying by monosaccharides and disaccharides in test meals. J Physiol 1968; 194: 317-26.

5 Carnot P, Chassevant A. Modifications subies, dans l'estomach et le duodenum par les solutions salines, suivant leur concentration moleculaire. Le reflexe regulateur du sphincter pylorique. C $R$ Soc Biol Paris 1905; 58: 173-6.

6 McSwinney BA, Spurrell WR. The influence of osmotic pressure on the emptying time of the stomach. $J$ Physiol 1933; 79: 437-42.

7 Hunt JD. The duodenal regulation of gastric emptying. Gastroenterology 1963; 43: 149-56.

8 Kelly KA. Motility of the stomach and gastroduodenal function. In: Johnson LR, ed., Physiology of the gastrointestinal tract. New York: Raven Press, 1981.

9 Dooley CP, Reznick JB, Valenzuela JE. A continuous manometric study of the human pylorus. Gastroenterology 1985; 89: 821-6.

10 Weisbrodt NW, Wiley JN, Overholt BF, Bass P. A relation between gastroduodenal muscle contractions and gastric emptying. Gut 1969; 10: 543-8.

11 Miller J, Kauffman G, Elashoff J, Ohashi H, Carter D, Meyer JH. Search for resistances controlling canine gastric emptying of liquid meals. Am J Physiol 1981; 241: G403-15.

12 Vantrappen G, Jannsens J, Hellemans J, Ghoos Y. The interdigestive motor complex of normal subjects and patients with bacterial overgrowth of the small intestine. J Clin Invest 1977; 59: 1158-66.

13 Sarna S, Northcott P, Belbeck L. Mechanism of cycling of migrating myoelectric complexes: effect of morphine. Am J Physiol 1982; 242: G588-95.

14 Thompson DG, Wingate DL, Archer L, Benson M, Green W, Hardy R. Normal patterns of human small bowel motor activity recorded by prolonged radiotelemetry. Gut 1980; 21 : 500-6.

15 Binfield P, DeBelder A, Thompson DG, Warren S, Wilson $M$, Wingate DL. The influence of duodenal intraluminal osmolality on intestinal transit. $J$ Physiol 1983; 343: 87-8P.

16 Seigel S. Non parametric statistics for the behavioural sciences. Tokyo: McGraw-Hill, 1956.

17 Thompson DG, Malagelada J-R. Vomiting and the small intestine. Dig Dis Sci 1982; 27: 1121-5. 
18 Gregory RA. Some factors influencing the passage of fluid through intestinal loops in dogs. J Physiol 1950; 111: $119-37$.

19 Summers RW. Modulation of jejunal flow by solutions of varying osmolality and acidity in the intact canine jejunum. Dig Dis Sci 1980; 25: 905-10.

20 Kendall GPN, Thompson DG, Day SJ. Motor responses of the small intestine to intraluminal distension in normal volunteers and patients with visceral neuropathy. Gut 1987. (In press.)

21 Lewis TD, Collins SM, Fox JE, Daniel E. Initiation of duodenal acid-induced motor complexes. Gastroenterology 1979; 77: 1217-24.

22 Gregory PC, Rayner DV, Wenham G. Initiation of migrating myoelectric complex in sheep by duodenal acidification and hyperosmolarity: role of vagus nerves. J Physiol 1984; 355: 509-21.

23 Thompson DG, Richelson E, Malagelada J-R. Perturbation of gastric emptying and duodenal motility via the central nervous system. Gastroenterology 1982; 83: $1200-6$.

24 Ravdin IS, Pendergrass EP, Johnston CG, Hodes PJ. The effect of foodstuffs on the emptying of the normal and operated stomach and the small intestinal pattern. AJR 1936; 35: 306-15.

25 Gershon-Cohen J, Shay H, Fels SS. Experimental studies on gastric physiology in man. IV. The influence of osmotic pressure changes of salt and sugar solutions on pyloric action and gastric emptying in the normal and operated stomach. AJR 1983; 40: 335-43.

26 Johnston CG, Ravdin IS. Action of glucose on emptying of stomach. Effect of varying concentrations in both normal stomachs and after various gastric operations. Am Surg 1935; 101: 500-5.

27 Nakayama S. Movements of the small intestine in transport of intraluminal contents. Jpn J Physiol 1962; 12: 522-33.

28 Fordtran JS, Locklear TW. Ionic constituents and osmolality of gastric and small intestinal fluids after eating. Am J Dig Dis 1966; 11: 503-21.

29 Mearin F, Azpiroz F, Malagelada J-R. Measurement of resistance to flow across antroduodenal area during fasting. Am J Physiol 1986; 250: G773-80.

30 McKelvey STD. Gastric incontinence and post-vagotomy diarrhoea. Br J Surg 1970; 57: 741-7.

31 Williams NS, Miller J, Elashoff J, Meyer JH. Canine resistances to gastric emptying of liquid nutrients after ulcer surgery. Dig Dis Sci 1986; 31: 273-80.

32 Gough MJ, Humphrey CS, Giles GR. Does osmotic control of gastric emptying persist after truncal vagotomy? Br J Surg 1981; 68: 77-80.

33 Ladas SD, Isaacs PET, Quereshi Y, Sladen G. Role of the small intestine in post vagotomy diarrhoea. Gastroenterology 1983; 85: 1088-93. 